\title{
Clinical prediction of delayed cerebral ischemia in aneurysmal subarachnoid hemorrhage
}

\author{
Hubert Lee, MD, MSc, ${ }^{1}$ Jeffrey J. Perry, MD, MSc, ${ }^{2}$ Shane W. English, MD, MSc, ${ }^{3}$ \\ Fahad Alkherayf, MD, MSc, CIP, FRCSC, ${ }^{1}$ Joanne Joseph, HBSc, ${ }^{4}$ Steven Nobile, BSc, ${ }^{4}$ \\ Linghong Linda Zhou, BHSc, ${ }^{4}$ Howard Lesiuk, MD, ${ }^{1}$ Richard Moulton, MD, ${ }^{1}$ Charles Agbi, MBBS, ${ }^{1}$ \\ John Sinclair, MD, ${ }^{1}$ and Dar Dowlatshahi, MD, PhD ${ }^{5}$
}

\begin{abstract}
'Division of Neurosurgery, The Ottawa Hospital, Ottawa; ${ }^{2}$ Department of Emergency Medicine, The Ottawa Hospital, Ottawa Hospital Research Institute, University of Ottawa; ${ }^{3}$ Department of Critical Care, The Ottawa Hospital, Ottawa; ${ }^{4}$ Faculty of Medicine, University of Ottawa; and ${ }^{5}$ Division of Neurology, The Ottawa Hospital, Ottawa, Ontario, Canada
\end{abstract}

\begin{abstract}
OBJECTIVE The aim of this study was to derive a clinically applicable decision rule using clinical, radiological, and laboratory data to predict the development of delayed cerebral ischemia (DCl) in aneurysmal subarachnoid hemorrhage (aSAH) patients.
\end{abstract}

METHODS Patients presenting over a consecutive 9-year period with subarachnoid hemorrhage (SAH) and at least 1 angiographically evident aneurysm were included. Variables significantly associated with $\mathrm{DCl}$ in univariate analysis underwent multivariable logistic regression. Using the beta coefficients, points were assigned to each predictor to establish a scoring system with estimated risks. $\mathrm{DCl}$ was defined as neurological deterioration attributable to arterial narrowing detected by transcranial Doppler ultrasonography, CT angiography, MR angiography, or catheter angiography, after exclusion of competing diagnoses.

RESULTS Of 463 patients, $58 \%$ experienced angiographic vasospasm with an overall DCl incidence of $21 \%$. Age, modified Fisher grade, and ruptured aneurysm location were significantly associated with $\mathrm{DCl}$. This combination of predictors had a greater area under the receiver operating characteristic curve than the modified Fisher grade alone $(0.73[95 \% \mathrm{Cl}$ $0.67-0.78$ ] vs 0.66 [ $95 \% \mathrm{Cl} 0.60-0.71]$ ). Patients 70 years or older with modified Fisher grade 0 or $1 \mathrm{SAH}$ and a posterior circulation aneurysm had the lowest risk of $\mathrm{DCl}$ at $1.2 \%$ (0 points). The highest estimated risk was $38 \%$ (17 points) in patients $40-59$ years old with modified Fisher grade $4 \mathrm{SAH}$ following rupture of an anterior circulation aneurysm.

CONCLUSIONS Among patients presenting with aSAH, this score-based clinical prediction tool exhibits increased accuracy over the modified Fisher grade alone and may serve as a useful tool to individualize DCl risk.

https://thejns.org/doi/abs/10.3171/2018.1.JNS172715

KEYWORDS delayed cerebral ischemia; vasospasm; subarachnoid hemorrhage; aneurysm; prediction; clinical decision rule; vascular disorders

$\mathrm{D}$ ELAYED cerebral ischemia (DCI) is the leading cause of preventable mortality and morbidity, accounting for $23 \%$ of deaths, $11 \%-15 \%$ of poor outcomes, and persistent neurological deficit in $37 \%$ of survivors. ${ }^{22,25,27}$ Several clinical and radiological features have been investigated as potential predictors of DCI in previous models. ${ }^{2,67,10,14,17,23,24}$ They identified neurological grade, clot thickness, aneurysm location, cerebral blood flow (CBF), age, cardiac vital signs, CSF drainage, intracranial pressure, and serum electrolytes as important variables; however, a practical clinical tool remains to be developed. These models are limited by outdated practices, study-specific aneurysmal subarachnoid hemorrhage (aSAH) scales, cumbersome measures of intraventricular

ABBREVIATIONS $\mathrm{aSAH}=$ aneurysmal $\mathrm{SAH} ; \mathrm{CBF}=$ cerebral blood flow; $\mathrm{DCl}=$ delayed cerebral ischemia; $\mathrm{DSA}=$ digital subtraction angiography; $\mathrm{EVD}=$ external ventricular drainage; IVH = intraventricular hemorrhage; ROC = receiver operating characteristic; $\mathrm{SAH}=$ subarachnoid hemorrhage; $\mathrm{TCD}=$ transcranial Doppler; WFNS = World Federation of Neurosurgical Societies.

SUBMITTED October 27, 2017. ACCEPTED January 10, 2018.

INCLUDE WHEN CITING Published online June 8, 2018; DOI: 10.3171/2018.1.JNS172715. 
hemorrhage (IVH), institution-specific technology to measure $\mathrm{CBF}$, and small sample size.

Timely diagnosis of DCI can be difficult, as the degree of arterial vessel-caliber reduction does not necessarily correlate with development of neurological symptoms. A clinical prediction rule, a mathematical tool using patient characteristics and investigation results to aid physicians in predicting DCI in aSAH, would allow early identification of patients who may benefit from aggressive prophylactic treatment, closer monitoring in an ICU, or repeat vascular imaging. Determining those at greatest risk can help reduce DCI-related poor outcomes while minimizing treatment complications and titrate ICU length of stay. The objective of this study was to derive a clinically applicable prediction rule based on routine clinical, radiological, and laboratory characteristics that identifies patients with aSAH who will develop DCI.

\section{Methods \\ Patient Population}

The health records of patients admitted between June 2002 and 2011 with subarachnoid hemorrhage (SAH) and an intracranial aneurysm were retrospectively reviewed at the Ottawa Hospital, a tertiary care institution and regional neurosurgical center. SAH was diagnosed by CT or CSF analysis demonstrating $>5 \times 10^{6} / \mathrm{L}$ red blood cells in the final test tube or xanthochromia up to 2 weeks after suspected aneurysmal rupture. ${ }^{20,21}$ Aneurysms were confirmed by CTA, MRA, or conventional digital subtraction angiography (DSA). Only patients older than 18 years presenting within the risk period for cerebral vasospasm were included. Death prior to day 4 post-aSAH, admission past day 14 post-aSAH, DCI at presentation, and aneurysms associated with arteriovenous malformations or of the mycotic or traumatic type were criteria for exclusion. Recruitment was completed using a validated text miner that searched radiology reports for keywords indicating aSAH and CSF analysis results within the Ottawa Hospital Data Warehouse. ${ }^{12}$ Search results were verified individually to ensure accuracy and that the inclusion and exclusion criteria were satisfied.

\section{Predictor Variables}

Data were collected for each patient related to their comorbidities, presentation, and in-hospital course. The clinical variables included were age, sex, cardiovascular risk factors, previous intracranial hemorrhage, smoking status, illicit drug use, medications, family history of aneurysms or aSAH, presenting neurological grade, systolic blood pressure, body temperature, and unit of admission. Age was analyzed as a continuous variable and a categorical variable by decades, with ages $18-39$ years and 70 years or older collapsed into single groups due to small numbers. Blood pressure and temperature were classified as continuous variables and dichotomized variables at 180 $\mathrm{mm} \mathrm{Hg}$ and $38^{\circ} \mathrm{C}$, respectively. Neurological grade was assessed using the World Federation of Neurosurgical Societies (WFNS) scale.

Radiological variables considered were modified Fisher grade $^{13}$ (classified by a single investigator reviewing all presenting CT head imaging), ruptured aneurysm location and maximum diameter, aneurysm multiplicity, hydrocephalus, and mean flow velocities recorded by transcranial Doppler (TCD) ultrasonography on days 2-14 postaSAH. TCD results were summarized as elevated (mean flow velocity $>120 \mathrm{~cm} / \mathrm{sec}$ and Lindegaard ratio $>3$ ), normal, or not performed. Management-related variables included the modality of aneurysm treatment; use of nimodipine, prophylactic statin, antiepileptic drugs, or nicotine replacement therapy; and required external ventricular drain (EVD) placement or endotracheal intubation within 24 hours of presentation or prior to day 4 post-aSAH. Complications entered as present or absent on day 3 postaSAH or earlier included seizures, hyponatremia, anemia, pulmonary edema, acute coronary syndrome, arrhythmia, and heart failure. The cutoffs used for hyponatremia and anemia were a serum sodium level $<135 \mathrm{mmol} / \mathrm{L}$ and hemoglobin level $\leq 100 \mathrm{~g} / \mathrm{L}$, respectively. Pulmonary edema was verified using chest radiographs. Acute coronary syndrome was considered present if clinical symptoms (chest pain, left arm pain, diaphoresis) or electrocardiogram changes accompanied elevated cardiac enzymes. The arrhythmias of interest were ventricular tachycardia, ventricular fibrillation, and supraventricular tachycardia. An echocardiogram demonstrating an ejection fraction less than $40 \%$ was required for a diagnosis of systolic heart failure.

\section{Definition and Assessment of $\mathrm{DCl}$}

DCI was defined as a focal neurological deficit attributable to a detected vascular territory of intracranial arterial narrowing (angiographic vasospasm) in the absence of alternative causes. The deficit could not be present immediately after aneurysm treatment and included hemiparesis, hemiparesthesia, aphasia, apraxia, neglect, hemianopia, and decreased level of consciousness equaling a loss of $\geq 2$ points on the Glasgow Coma Scale..$^{29}$ Changes in neurological status were determined from chart review, and arterial narrowing was diagnosed from radiology reports documenting vasospasm of all severities on CT, MR, or DSA, or elevation in TCD velocities meeting the criteria for vasospasm. Outcome assessment was divided among 3 investigators blinded to the identity of the predictor variables. Uncertainty about the outcome was adjudicated by a fourth investigator. Interrater reliability was determined based on a pilot cohort of 25 patients using the $(2,1)$ form of the Shrout-Fleiss intraclass correlation coefficient with each rater considered a random effect. ${ }^{26}$ The results from this initial evaluation period were included in subsequent analysis.

\section{Logistic Regression}

The associations between the chosen predictor variables and DCI were characterized by univariate analysis using the chi-square or Fisher exact test and 2-sided t-test for categorical and continuous variables, respectively. Only those variables available at the time of presentation up to day 3 post-aSAH were considered. Candidate variables meeting a conservative $\mathrm{p}$ value $<0.20$ underwent multivariate logistic regression using stepwise backward selection, and 
those reaching statistical significance $(\mathrm{p}<0.05)$ were retained. Odds ratios with corresponding 95\% confidence intervals were calculated describing the contribution of each predictor to the occurrence of DCI. Model fit was assessed using the Hosmer-Lemeshow test and its discrimination determined by receiver operating characteristic (ROC) curve analysis. The area under the ROC curve of the derived model was compared to the performance of the modified Fisher grade alone. All analyses were performed using SAS software (version 9.4, SAS Institute Inc.).

Using accepted methods, a risk score was developed based on the estimated beta coefficients from the final multivariate logistic regression model. ${ }^{28}$ The smallest coefficient was assigned as the constant for the point system representing a point of 1 . Values for the remaining risk factors were assigned by dividing the associated beta coefficient by the point system constant and rounding to the nearest 0.5 . The estimated risk of DCI associated with each point total was calculated using the methods described by Sullivan et al. and the corresponding sensitivity and specificity for each score cutoff were determined..$^{28}$

\section{Results}

From the cohort of 568 aSAH patients identified by the text miner, 463 were included in this study. The most common criterion for exclusion was death prior to day 4 post-aSAH, accounting for $75(71.43 \%)$ of the excluded patients. Two unruptured aneurysms undergoing endovascular coiling complicated by intraoperative rupture were included and analyzed, as they met predefined inclusion criteria. It was not possible to perform a meaningful sensitivity analysis comparing spontaneous to iatrogenic ruptured aneurysms due to small numbers.

The mean age \pm SD at presentation was $56.0 \pm 13.2$ years, and the majority of patients were female (70.2\%). Almost half the patients had a history of hypertension and current smoking (46.0\% and $48.0 \%$, respectively). Neurological grade at presentation was generally good, with $50.5 \%$ of patients having WFNS grade I and only $13.2 \%$ having WFNS grade V. Thick SAH with IVH was observed on CT in $41.7 \%$ of patients, corresponding to a modified Fisher grade 4; $14.5 \%$ SAHs were modified Fisher grade 3,17.9\% were modified Fisher grade 2, and 25.9\% were modified Fisher grade 1 or 0. Lumbar puncture was used to diagnose 27 patients whose CT scan was negative for SAH. Anterior circulation aneurysms predominated at $82.5 \%$. TCD ultrasonography was only performed in $34.6 \%$ of patients, with $3.9 \%$ demonstrating elevated velocities. A greater proportion of aneurysms underwent endovascular coiling (57.0\%) than surgical clipping (43.0\%). CSF diversion via EVD placement was required by $31.3 \%$ patients.

Angiographic vasospasm was detected by CTA, MRA, DSA, or TCD ultrasonography in $57.7 \%$ of patients, of whom just over one-third exhibited attributable neurological symptoms. The resulting overall incidence of DCI in this cohort was $21.0 \%$. The distribution of clinical features, radiological findings, treatments, and complications between those who developed DCI and those who did not is detailed in Table 1. While just under $50 \%$ of patients
TABLE 1. Demographic, clinical, and radiological characteristics of 463 patients presenting with aSAH

\begin{tabular}{|c|c|c|c|}
\hline Characteristic & $\begin{array}{l}\text { Pts w/ } \\
\text { Delayed } \\
\text { Cerebral } \\
\text { Ischemia } \\
(n=97)\end{array}$ & $\begin{array}{l}\text { Pts w/o } \\
\text { Delayed } \\
\text { Cerebral } \\
\text { Ischemia } \\
(n=366)\end{array}$ & $\begin{array}{c}p \\
\text { Value }\end{array}$ \\
\hline \multicolumn{4}{|l|}{ Demographics } \\
\hline \multicolumn{4}{|l|}{ Age, yrs } \\
\hline Mean & $54.62 \pm 11.56$ & $56.35 \pm 13.58$ & 0.25 \\
\hline$<40$ & $7(7.2)$ & $39(10.7)$ & \multirow{5}{*}{0.15} \\
\hline $40-49$ & $26(26.8)$ & $80(21.9)$ & \\
\hline $50-59$ & $34(35.1)$ & $107(29.2)$ & \\
\hline $60-69$ & $20(20.6)$ & $67(18.3)$ & \\
\hline$\geq 70$ & $10(10.3)$ & $73(20.0)$ & \\
\hline No. of females & $73(75.3)$ & $252(68.9)$ & 0.22 \\
\hline \multicolumn{4}{|l|}{ Comorbidities } \\
\hline Hypertension & $42(43.3)$ & $171(46.7)$ & 0.55 \\
\hline Hypercholesterolemia & $11(11.3)$ & $53(14.5)$ & 0.43 \\
\hline Diabetes & $7(7.2)$ & $32(8.7)$ & 0.84 \\
\hline Coronary artery disease & $10(10.3)$ & $35(9.6)$ & 0.85 \\
\hline Stroke & $2(2.1)$ & $16(4.4)$ & 0.39 \\
\hline $\begin{array}{l}\text { Connective tissue } \\
\text { disorder }\end{array}$ & $2(2.1)$ & $2(0.6)$ & 0.19 \\
\hline Sickle cell disease & $0(0.0)$ & $1(0.3)$ & $>0.99$ \\
\hline Current smoker & $51(52.6)$ & $171(46.7)$ & 0.30 \\
\hline $\begin{array}{l}\text { Cocaine/amphetamine } \\
\text { use }\end{array}$ & $2(2.1)$ & $7(1.9)$ & $>0.99$ \\
\hline $\begin{array}{l}\text { Previous hemorrhage } \\
(\mathrm{SAH} / \mathrm{ICH} / \mathrm{IVH})\end{array}$ & $2(2.1)$ & $10(2.7)$ & $>0.99$ \\
\hline $\begin{array}{l}\text { Family history of aneu- } \\
\text { rysms or SAH }\end{array}$ & $9(9.3)$ & $39(10.7)$ & 0.85 \\
\hline \multicolumn{4}{|l|}{ Home medications } \\
\hline Statin & $9(9.3)$ & $56(15.3)$ & 0.14 \\
\hline Antiplatelet & $11(11.3)$ & $60(16.4)$ & 0.22 \\
\hline Anticoagulant & $1(1.0)$ & $10(2.7)$ & 0.47 \\
\hline \multicolumn{4}{|l|}{$\begin{array}{l}\text { Clinical features at presen- } \\
\text { tation }\end{array}$} \\
\hline WFNS grade & & & 0.02 \\
\hline I & $35(36.1)$ & $199(54.4)$ & \\
\hline$\|$ & $18(18.6)$ & $44(12.0)$ & \\
\hline III & $8(8.3)$ & $15(4.1)$ & \\
\hline IV & $20(20.6)$ & $63(17.2)$ & \\
\hline V & $16(16.5)$ & $45(12.3)$ & \\
\hline $\begin{array}{l}\text { Mean systolic blood pres- } \\
\text { sure, } \mathrm{mm} \mathrm{Hg}\end{array}$ & $161 \pm 34.63$ & $157.5 \pm 30.18$ & 0.33 \\
\hline Mean temperature, ${ }^{\circ} \mathrm{C}$ & $36.23 \pm 0.92$ & $36.22 \pm 0.96$ & 0.95 \\
\hline ICU admission & $45(46.4)$ & $120(32.8)$ & 0.01 \\
\hline \multicolumn{4}{|l|}{ Radiological findings } \\
\hline Modified Fisher grade & & & $<0.0001$ \\
\hline $0 / 1$ & $11(11.3)$ & $109(29.8)$ & \\
\hline 2 & $8(8.3)$ & $75(20.5)$ & \\
\hline 3 & $21(21.7)$ & $46(12.6)$ & \\
\hline 4 & $57(58.8)$ & $136(37.2)$ & \\
\hline
\end{tabular}


" CONTINUED FROM PAGE 1916

TABLE 1. Demographic, clinical, and radiological characteristics of 463 patients presenting with aSAH

\begin{tabular}{|c|c|c|c|}
\hline Characteristic & $\begin{array}{l}\text { Pts w/ } \\
\text { Delayed } \\
\text { Cerebral } \\
\text { Ischemia } \\
(n=97)\end{array}$ & $\begin{array}{l}\text { Pts w/o } \\
\text { Delayed } \\
\text { Cerebral } \\
\text { Ischemia } \\
(n=366)\end{array}$ & $\begin{array}{c}\mathrm{p} \\
\text { value }\end{array}$ \\
\hline \multicolumn{4}{|l|}{$\begin{array}{l}\text { Radiological findings (con- } \\
\text { tinued) }\end{array}$} \\
\hline Location & & & 0.002 \\
\hline Posterior circulation & $7(7.2)$ & $74(20.2)$ & \\
\hline $\begin{array}{l}\text { Posterior communi- } \\
\text { cating artery }\end{array}$ & $17(17.5)$ & $63(17.2)$ & \\
\hline $\begin{array}{l}\text { Internal carotid } \\
\text { artery }\end{array}$ & $6(6.2)$ & 37 (10.1) & \\
\hline $\begin{array}{l}\text { Middle cerebral } \\
\text { artery }\end{array}$ & $29(29.9)$ & $68(18.6)$ & \\
\hline $\begin{array}{l}\text { Anterior cerebral } \\
\text { artery }\end{array}$ & $3(3.1)$ & $14(3.8)$ & \\
\hline $\begin{array}{l}\text { Anterior communi- } \\
\text { cating artery }\end{array}$ & $35(36.1)$ & $110(30.1)$ & \\
\hline $\begin{array}{l}\text { Mean diameter of } \\
\text { ruptured aneurysm, } \\
\text { mm }\end{array}$ & $6.61 \pm 3.69$ & $7.27 \pm 4.06$ & 0.15 \\
\hline $\begin{array}{l}\text { No. of pts w/ multiple } \\
\text { aneurysms }\end{array}$ & $29(29.9)$ & $124(33.9)$ & 0.46 \\
\hline $\begin{array}{l}\text { Mean total no. of } \\
\text { aneurysms }\end{array}$ & $1.47 \pm 0.91$ & $1.49 \pm 0.88$ & 0.86 \\
\hline Hydrocephalus & $54(55.7)$ & $173(47.3)$ & \\
\hline $\begin{array}{l}\text { TCD ultrasonography } \\
\text { (SAH day } 3 \text { or prior) }\end{array}$ & & & 0.14 \\
\hline Elevated & $7(7.2)$ & $11(3.0)$ & \\
\hline Normal & $31(32.0)$ & $111(30.3)$ & \\
\hline Not performed & $59(60.8)$ & $244(66.7)$ & \\
\hline \multicolumn{4}{|l|}{ Treatment } \\
\hline Surgical clipping* & $47(49.5)$ & $147(41.3)$ & 0.15 \\
\hline Endovascular coiling* & $48(50.5)$ & $209(58.7)$ & \\
\hline Nimodipine & $97(100.0)$ & $361(98.6)$ & 0.59 \\
\hline Statin & $49(50.5)$ & $141(38.5)$ & 0.03 \\
\hline Antiepileptic drug & $94(96.9)$ & $343(93.7)$ & 0.32 \\
\hline $\begin{array}{l}\text { Nicotine replacement } \\
\text { therapy }\end{array}$ & $4(4.1)$ & $16(4.4)$ & $>0.99$ \\
\hline \multicolumn{4}{|l|}{$\begin{array}{l}\text { Complication (SAH day } 3 \\
\text { or prior) }\end{array}$} \\
\hline EVD placement & $39(40.2)$ & $106(29.0)$ & 0.03 \\
\hline Seizures & $20(20.6)$ & $52(14.2)$ & 0.12 \\
\hline Intubation & $41(42.3)$ & $113(30.9)$ & 0.03 \\
\hline Pulmonary edema & $12(12.4)$ & 48 (13.1) & 0.85 \\
\hline Cardiac & $10(10.3)$ & $33(9.0)$ & 0.70 \\
\hline $\begin{array}{l}\text { Hyponatremia }(<135 \\
\mathrm{mmol} / \mathrm{L})\end{array}$ & $16(16.5)$ & $54(14.8)$ & 0.67 \\
\hline Anemia ( $\leq 100 \mathrm{~g} / \mathrm{L})$ & $21(21.7)$ & $76(20.8)$ & 0.85 \\
\hline
\end{tabular}

$\mathrm{ICH}=$ intracerebral hemorrhage; pts = patients.

* Twelve aneurysms did not undergo occlusive treatment due to poor neurological condition. were discharged home from the hospital, the case fatality rate of aSAH was $14.3 \%$. Those who acquired DCI had a marginally higher mortality rate at $16.5 \%$ (no DCI: $13.7 \%$ ) and substantially reduced discharge home, $38.1 \%$ (no DCI: $52.5 \%)$.

\section{Interrater Reliability}

The percentage agreement among the 3 outcome assessors for the pilot aSAH cohort was $85.3 \%$. An identical diagnosis by all assessors occurred in 20 of 25 cases. The Shrout-Fleiss intraclass correlation coefficient was 0.84 (95\% CI 0.71-0.92), indicating good interrater reliability in identifying DCI.

\section{Logistic Regression}

A total of 14 variables were significantly associated with DCI at $\mathrm{p}<0.20$ (Table 1). These included age, history of connective tissue disorder, home statin use, WFNS grade, ICU admission, modified Fisher grade, aneurysm location, aneurysm diameter, early elevated TCD velocities, modality of aneurysm treatment, statin prophylaxis, EVD placement, seizures prior to admission, and early intubation. TCD ultrasonography results did not undergo further analysis, as there was a great amount of missing information, with 303 patients who did not undergo this examination.

After fitting the variables significant from univariate analysis into an initial multivariable model, only age, modified Fisher grade, and aneurysm location remained predictive of DCI (Table 2). For age, being younger than 40 years and 60-69 years did not reach significance when compared to age $\geq 70$ years. Similarly, modified Fisher grade 2 in relation to grade 1 had a $p$ value $>0.05$. The Hosmer-Lemeshow test of the multivariable model did not show evidence of poor fit $(p=0.82)$. Discrimination was acceptable with an area under the ROC curve of 0.73 (95\% CI 0.67-0.78), greater than the modified Fisher grade alone (0.66 [95\% CI 0.60-0.71]).

\section{Score Derivation}

The smallest estimated coefficient, 0.23 from the relationship between modified Fisher grade 2 and grade 1, was assigned a point equivalence of 1 and used as the score constant from which the point values for the remaining covariate categories were designated (Table 2). This resulted in a score containing 3 clinicoradiographic variables totaling 0-17 points and associated with an estimated risk of DCI of 1\%-38\% (Table 3). Figure 1 illustrates the sensitivities and specificities for all possible score cutoffs.

\section{Discussion \\ Factors Predictive of $\mathrm{DCl}$}

We derived a clinical decision rule to predict DCI using 3 predictors: age, amount of SAH on presentation, and ruptured aneurysm location. This decision rule achieves improved estimation of an individual's DCI risk beyond the modified Fisher grade alone. A recently proposed risk chart identified age dichotomized at 55 years as an important prognostic factor. ${ }^{7}$ We characterize this risk between decades in a contemporary study population where endo- 
TABLE 2. Multivariable logistic regression model predicting $\mathrm{DCl}$ in aSAH and derivation of the $\mathrm{DCl}$ score

\begin{tabular}{|c|c|c|c|c|c|c|}
\hline Predictor & Estimated $\beta$ Coefficient & SE & Estimated OR & $95 \% \mathrm{Cl}$ & $p$ Value & Points $=\beta$ Coefficient $/ B$ \\
\hline Intercept & -4.42 & 0.6636 & & & $<0.0001$ & \\
\hline \multicolumn{7}{|l|}{ Age, yrs } \\
\hline$<40$ & 0.85 & 0.59 & 2.34 & $0.74-7.36$ & 0.15 & 4 \\
\hline $40-49$ & 1.20 & 0.45 & 3.33 & $1.39-7.97$ & 0.007 & 5 \\
\hline $50-59$ & 1.18 & 0.43 & 3.22 & $1.40-7.42$ & 0.006 & 5 \\
\hline $60-69$ & 0.69 & 0.46 & 1.99 & $0.82-4.87$ & 0.13 & 3 \\
\hline$\geq 70$ & Reference & & & & & 0 \\
\hline \multicolumn{7}{|c|}{ Modified Fisher grade } \\
\hline $0 / 1$ & Reference & & & & & 0 \\
\hline 2 & 0.23 & 0.50 & 1.26 & $0.48-3.34$ & 0.64 & 1 \\
\hline 3 & 1.49 & 0.42 & 4.46 & $1.96-10.13$ & 0.0004 & 6 \\
\hline 4 & 1.70 & 0.37 & 5.45 & $2.62-11.33$ & $<0.0001$ & 7 \\
\hline \multicolumn{7}{|c|}{ Aneurysm location } \\
\hline Anterior & 1.26 & 0.43 & 3.54 & $1.51-8.29$ & 0.004 & 5 \\
\hline Posterior & Reference & & & & & 0 \\
\hline
\end{tabular}

$B=$ constant for the point system ( 0.23 from modified Fisher grade 2$)$.

vascular coiling is increasingly prevalent. Dumont and colleagues' artificial neural network also included age; however, the variable "age" was entered with presumed importance and its individual contribution is difficult to interpret. ${ }^{10}$ A 2013 systematic review concluded "inconsistent evidence" from studies supporting greater risk in younger patients, ${ }^{3}$ with increasing age,${ }^{30}$ or no difference with age. ${ }^{8,23}$ Macdonald and colleagues' description of DCI risk peaking for ages 40-59 years mirrors our findings. ${ }^{18}$ Senescent intracranial arteries become increasingly stiff with reduced elasticity from vessel wall thickening, increased thickness-to-radius ratio, and collagen fiber formation. ${ }^{15,16}$ This, along with atherosclerosis, may render elderly patients more resistant to vasospasm with the ability to maintain luminal patency in the setting of restricted CBF. Why younger patients experienced lower rates of DCI is uncertain but perhaps reflects an increased resilience to ischemia and preservation of autoregulation. This is suggested by the loss of association between the reversibility of neurological deterioration secondary to angiographic vasospasm and severity of vessel narrowing with increasing age where cardiorespiratory comorbidities are increasingly prevalent. ${ }^{31}$

The amount of initial SAH has a robust association to DCI regardless of its classification. . $10,14,17,23^{\text {The modified }}$ Fisher grade, which we demonstrated to independently increase susceptibility to DCI with higher grade, has only been studied in other models when collapsed into thin or thick SAH despite improved prognostication by incorporating IVH status. ${ }^{4,67,13}$ De Rooij and colleagues' risk chart recognized the contribution of $\mathrm{IVH}$, quantifying it using the Hijdra score.? This score's complexity comprises overall feasibility and is likely the reason it was removed in the VASOGRADE, a subsequent external validation study. ${ }^{6} \mathrm{~A}$ multivariate analysis of 218 aSAH patients demonstrated the modified Fisher grade to be a significant risk factor for DCI with an OR of 2.99 (95\% CI 2.05-4.35). ${ }^{30} \mathrm{We}$ did not find a difference between modified Fisher grades 1 and 2, representing the absence or presence of IVH accompanying thin SAH. Only 8 cases of grade $2 \mathrm{aSAH}$ were associated with DCI, resulting in insufficient power. EVD placement prior to day 4 post-SAH did significantly alter the influence of having a modified Fisher grade 4 versus grade $3 \mathrm{aSAH}$ when included in the multivariable model such that the grades' odds ratios were practically equivalent, negating the importance of IVH. If true, the deleterious effects of hemorrhagic products in CSF can be minimized by enhanced clearance through CSF drainage. Omission of EVD placement from the final prediction rule

TABLE 3. Estimated risk of $D C l$ based on the point total from the $\mathrm{DCl}$ score

\begin{tabular}{ccc}
\hline Point Total & Estimate of Risk (\%) & Risk Group \\
\hline 0 & 1.2 & \\
\hline 1 & 1.5 & \\
\hline 3 & 2.4 & Low \\
\hline 4 & 3.0 & \\
\hline 5 & 3.7 & \\
\hline 6 & 4.6 & \\
\hline 7 & 5.8 & \\
\hline 8 & 7.2 & \\
\hline 9 & 8.9 & Moderate \\
\hline 10 & 10.9 & \\
\hline 11 & 13.4 & \\
\hline 12 & 16.3 & High \\
\hline 14 & 23.7 & \\
\hline 15 & 28.2 & \\
\hline 16 & 33.1 & \\
\hline 17 & 38.4 &
\end{tabular}




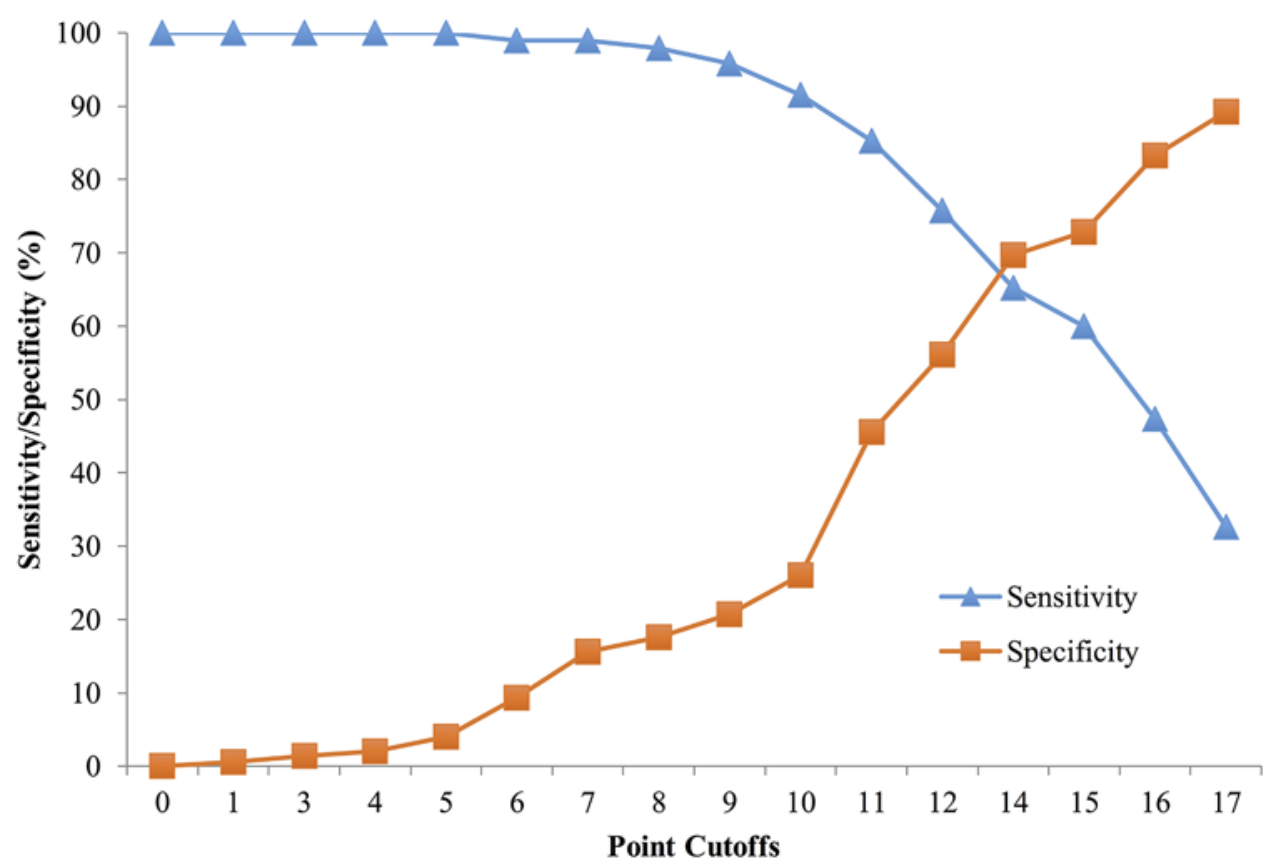

FIG. 1. Sensitivity and specificity of the delayed cerebral ischemia score for all point cutoffs. Figure is available in color online only.

stems from the possibility that the modified Fisher grade influences EVD insertion, allowing a change of a patient's risk score in real time, if included.

Ruptured posterior circulation aneurysms were less likely to precipitate DCI than anterior circulation aneurysms. Qureshi and colleagues' risk index also identified anterior cerebral and internal carotid artery aneurysms as high-risk features. ${ }^{23}$ The relationship between aneurysm location and DCI has previously been investigated. Posterior cerebral artery aneurysms were protective against DCI with an OR of 0.05 (95\% CI 0.01-0.41). ${ }^{19}$ Abla et al. determined that rupture of vertebral and basilar artery aneurysms resulted in the second and third lowest mean SAH maximum thickness behind pericallosal artery aneurysms. ${ }^{1}$ While this association with SAH thickness could explain our observed difference in DCI incidence, it is doubtful, as the proportion of aSAHs classified as modified Fisher grades 3 and 4 was comparable between locations (anterior: 56.5\%, posterior: 54.3\%).

\section{Incidence of DCI and Proposed Clinical Decision Rule}

The DCI score estimates the risk to be $1.2 \%$ in a $\geq$ 70-year-old patient with thin to absent SAH, no IVH, and a posterior circulation aneurysm. A patient $40-59$ years old with thick SAH, IVH, and an anterior circulation aneurysm is at highest risk, estimated at $38.4 \%$. This range differs from Qureshi and colleagues' point-based risk index due to differing incidence. ${ }^{23}$ When all risk factors are present in both scores, the probability of developing DCI almost doubles. ${ }^{23}$ Our observed rate falls in the lower end of the range ( $20 \%$ to $43.2 \%$ ) from previously published prediction models whose outcome definitions varied. 2,6,7,10,14,17,23,24 Reduced diagnosis of DCI may have resulted from the requirement for attributable angiographic vasospasm. However, the artificial neural network of Dumont et al. used an identi- cal outcome definition, resulting in 39 cases $(35 \%) .{ }^{10}$ The lowest incidence was observed in de Rooij and colleagues' validation cohort-20\% - where radiographic evidence of infarction was required? The incidence of DCI has decreased from $32.5 \%$ in studies published prior to 1994 to 28.5\% in studies published between 1994 and 2009, during which aSAH management has changed, affecting complication rates and outcome. ${ }^{9}$ With calcium channel blocker prophylaxis (nimodipine or nicardipine) in 32 publications, this proportion declined to $22 \%$. Nimodipine administration in this study occurred in all but 3 patients, explaining the lower incidence as well as suggesting efficacy of this prophylactic agent. A recent study investigating the role of aneurysm location on aSAH outcomes similarly found neurological deterioration with angiographic vasospasm in $22 \%$ of patients who all received nimodipine. ${ }^{1}$ It is recognized that our definition of DCI potentially missed cases precipitated by mechanisms other than proximal arterial narrowing, including microvascular vasospasm, microthromboembolism, and cortical spreading ischemia.

The current practice in aSAH management is to monitor all patients as high risk for DCI, particularly until after the peak onset period for vasospasm of 6-8 days after aSAH. The VASOGRADE and de Rooij and colleagues' risk chart identified predictors (age, initial neurological grade, thickness of SAH, and IVH) available at the time of presentation with the same aim as this study for early risk stratification to tailor patient monitoring, treatment, and disposition. ${ }^{6,7}$ Classifying age into decades and the addition of aneurysm location in our model improved discriminative performance with a greater area under the ROC curve ( 0.73 [current study] vs 0.63 [de Oliveira Manoel et al. ${ }^{6}$ ] vs 0.63 [de Rooij et al..$^{7}$ ]). In choosing a score cutoff, clinicians are more likely to accept over-diagnosing DCI, as missed cases can lead to serious morbidity or even mortality. A DCI score of $\leq 9$ is proposed to represent a low- 
risk group having less than half the estimated risk $(<10 \%)$ of developing DCI and high sensitivity near or at $100 \%$ for scores lower than 7. Sensitivity approaches specificity at a score of 14 , where the estimated risk $(28.2 \%)$ begins to exceed the population incidence, suggesting scores $\geq 15$ to be a high-risk group.

\section{Study Limitations}

The major limitation of this study is its retrospective nature, which may have led to diagnosis misclassification of DCI, failure to identify important comorbidities, and precluded standardization of CBF monitoring. While this could contribute to the lower incidence of DCI observed, it remains within the expected range when considering newer studies implementing routine nimodipine administration. ${ }^{9}$ The proportions for cardiovascular risk factors, hypertension and diabetes specifically, were also consistent with those of previous studies (hypertension: $25 \%-44 \%,{ }^{18}$ diabetes: $\left.3 \%-9 \%{ }^{8}\right) .{ }^{11}$ Patients whose altered neurological status was successfully treated medically were potentially at risk of misclassification as not experiencing DCI, which could alter the observed association of certain predictors with DCI. This situation would be conceivably rare, attributable only to transient arterial narrowing or alternate etiologies to vasospasm. Lastly, a high percentage of our cohort presented with good neurological grade, known to be associated with reduced risk of developing DCI. ${ }^{6,7,23}$ This skewed distribution, although similarly observed in other studies investigating presenting neurological grade as a risk factor, could have reduced power in our outcome analysis and may explain why WFNS grade did not remain significant in the multivariate logistic regression model. ${ }^{5,6,8}$ Prior to clinical use, our proposed rule requires prospective evaluation in multiple institutions to capture variability in practice and aSAH populations.

\section{Conclusions}

Clinical and radiographic features available early in the presentation of aSAH can be used to reliably predict the onset of DCI. These risk factors include amount and distribution of SAH on initial CT, age, and ruptured aneurysm location. Their combined contributions in our proposed clinical decision rule improved predictive value over SAH thickness as classified by the modified Fisher grade, the only prognostic factor currently widely used in the management of this disease. It suggests patients 40 to 59 years old with a ruptured anterior circulation aneurysm and thick SAH are at high risk and should be considered for more aggressive monitoring in an ICU setting with frequent cerebrovascular imaging. Once prospectively validated in other neurosurgical centers, this rule may prove clinically useful to individualize DCI risk in aSAH patients.

\section{Acknowledgments}

Lily Polesello assisted with medical records acquisition. Monica Taljaard provided statistical advice regarding interrater reliability. Marie-Helen Roy-Gagnon provided statistical advice regarding logistic regression modelling.

Funding for this study was provided by Canadian Institutes of Health Research (CIHR) through the Frederick Banting and Charles Best Canada Graduate Scholarship.

\section{References}

1. Abla AA, Wilson DA, Williamson RW, Nakaji P, McDougall CG, Zabramski JM, et al: The relationship between ruptured aneurysm location, subarachnoid hemorrhage clot thickness, and incidence of radiographic or symptomatic vasospasm in patients enrolled in a prospective randomized controlled trial. J Neurosurg 120:391-397, 2014

2. Adams HP Jr, Kassell NF, Torner JC, Haley EC Jr: Predicting cerebral ischemia after aneurysmal subarachnoid hemorrhage: influences of clinical condition, CT results, and antifibrinolytic therapy. A report of the Cooperative Aneurysm Study. Neurology 37:1586-1591, 1987

3. Charpentier C, Audibert G, Guillemin F, Civit T, Ducrocq X, Bracard S, et al: Multivariate analysis of predictors of cerebral vasospasm occurrence after aneurysmal subarachnoid hemorrhage. Stroke 30:1402-1408, 1999

4. Claassen J, Bernardini GL, Kreiter K, Bates J, Du YE, Copeland D, et al: Effect of cisternal and ventricular blood on risk of delayed cerebral ischemia after subarachnoid hemorrhage: the Fisher scale revisited. Stroke 32:2012-2020, 2001

5. Crobeddu E, Mittal MK, Dupont S, Wijdicks EFM, Lanzino G, Rabinstein AA: Predicting the lack of development of delayed cerebral ischemia after aneurysmal subarachnoid hemorrhage. Stroke 43:697-701, 2012

6. de Oliveira Manoel AL, Jaja BN, Germans MR, Yan H, Qian W, Kouzmina E, et al: The VASOGRADE: a simple grading scale for prediction of delayed cerebral ischemia after subarachnoid hemorrhage. Stroke 46:1826-1831, 2015

7. de Rooij NK, Greving JP, Rinkel GJE, Frijns CJM: Early prediction of delayed cerebral ischemia after subarachnoid hemorrhage: development and validation of a practical risk chart. Stroke 44:1288-1294, 2013

8. de Rooij NK, Rinkel GJE, Dankbaar JW, Frijns CJM: Delayed cerebral ischemia after subarachnoid hemorrhage: a systematic review of clinical, laboratory, and radiological predictors. Stroke 44:43-54, 2013

9. Dorsch N: A clinical review of cerebral vasospasm and delayed ischaemia following aneurysm rupture. Acta Neurochir Suppl 110:5-6, 2011

10. Dumont TM, Rughani AI, Tranmer BI: Prediction of symptomatic cerebral vasospasm after aneurysmal subarachnoid hemorrhage with an artificial neural network: feasibility and comparison with logistic regression models. World Neurosurg 75:57-63, 25-28, 2011

11. Dumont T, Rughani A, Silver J, Tranmer BI: Diabetes mellitus increases risk of vasospasm following aneurysmal subarachnoid hemorrhage independent of glycemic control. Neurocrit Care 11:183-189, 2009

12. English SW, McIntyre L, Fergusson D, Turgeon A, Sun C, dos Santos MP, et al: Enriched administrative data can be used to retrospectively identify all known cases of primary subarachnoid hemorrhage. J Clin Epidemiol 70:146-154, 2016

13. Frontera JA, Claassen J, Schmidt JM, Wartenberg KE, Temes $\mathrm{R}$, Connolly ES Jr, et al: Prediction of symptomatic vasospasm after subarachnoid hemorrhage: the modified fisher scale. Neurosurgery 59:21-27, 2006

14. Gonzalez NR, Boscardin WJ, Glenn T, Vinuela F, Martin NA: Vasospasm probability index: a combination of transcranial Doppler velocities, cerebral blood flow, and clinical risk factors to predict cerebral vasospasm after aneurysmal subarachnoid hemorrhage. J Neurosurg 107:1101-1112, 2007

15. Hayashi K, Handa H, Nagasawa S, Okumura A, Moritake K: Stiffness and elastic behavior of human intracranial and extracranial arteries. J Biomech 13:175-184, 1980

16. Hegedüs K, Molnár P: Age-related changes in reticulin fibers and other connective tissue elements in the intima of the major intracranial arteries. Clin Neuropathol 8:92-97, 1989

17. Hijdra A, van Gijn J, Nagelkerke NJ, Vermeulen M, van 
Crevel H: Prediction of delayed cerebral ischemia, rebleeding, and outcome after aneurysmal subarachnoid hemorrhage. Stroke 19:1250-1256, 1988

18. Macdonald RL, Rosengart A, Huo D, Karrison T: Factors associated with the development of vasospasm after planned surgical treatment of aneurysmal subarachnoid hemorrhage. J Neurosurg 99:644-652, 2003

19. McGirt MJ, Mavropoulos JC, McGirt LY, Alexander MJ, Friedman AH, Laskowitz DT, et al: Leukocytosis as an independent risk factor for cerebral vasospasm following aneurysmal subarachnoid hemorrhage. J Neurosurg 98:1222-1226, 2003

20. Perry JJ, Stiell IG, Sivilotti MLA, Bullard MJ, Emond M, Symington C, et al: Sensitivity of computed tomography performed within six hours of onset of headache for diagnosis of subarachnoid haemorrhage: prospective cohort study. BMJ 343:d4277, 2011

21. Perry JJ, Stiell IG, Sivilotti MLA, Bullard MJ, Hohl CM, Sutherland J, et al: Clinical decision rules to rule out subarachnoid hemorrhage for acute headache. JAMA 310:12481255,2013

22. Proust F, Hannequin D, Langlois O, Freger P, Creissard P: Causes of morbidity and mortality after ruptured aneurysm surgery in a series of 230 patients. The importance of control angiography. Stroke 26:1553-1557, 1995

23. Qureshi AI, Sung GY, Razumovsky AY, Lane K, Straw RN, Ulatowski JA: Early identification of patients at risk for symptomatic vasospasm after aneurysmal subarachnoid hemorrhage. Crit Care Med 28:984-990, 2000

24. Roederer A, Holmes JH, Smith MJ, Lee I, Park S: Prediction of significant vasospasm in aneurysmal subarachnoid hemorrhage using automated data. Neurocrit Care 21:444-450, 2014

25. Ropper AH, Zervas NT: Outcome 1 year after SAH from cerebral aneurysm. Management morbidity, mortality, and functional status in 112 consecutive good-risk patients. J Neurosurg 60:909-915, 1984

26. Shrout PE, Fleiss JL: Intraclass correlations: uses in assessing rater reliability. Psychol Bull 86:420-428, 1979

27. Solenski NJ, Haley ECJ Jr, Kassell NF, Kongable G, Germanson T, Truskowski L, et al: Medical complications of aneurysmal subarachnoid hemorrhage: a report of the multicenter, cooperative aneurysm study. Participants of the Multicenter Cooperative Aneurysm Study. Crit Care Med 23:1007-1017, 1995

28. Sullivan LM, Massaro JM, D’Agostino RB Sr: Presentation of multivariate data for clinical use: The Framingham Study risk score functions. Stat Med 23:1631-1660, 2004

29. Vergouwen MDI, Vermeulen M, van Gijn J, Rinkel GJE, Wijdicks EF, Muizelaar JP, et al: Definition of delayed cerebral ischemia after aneurysmal subarachnoid hemorrhage as an outcome event in clinical trials and observational studies: proposal of a multidisciplinary research group. Stroke 41:2391-2395, 2010

30. Yin L, Ma CY, Li ZK, Wang DD, Bai CM: Predictors analysis of symptomatic cerebral vasospasm after subarachnoid hemorrhage. Acta Neurochir Suppl 110:175-178, 2011

31. Yoshimoto Y, Kwak S: Age-related multifactorial causes of neurological deterioration after early surgery for aneurysmal subarachnoid hemorrhage. J Neurosurg 83:984-988, 1995

\section{Disclosures}

Dr. English: support of non-study-related clinical or research effort from Canadian Blood Services and Canadian Institutes of Health Research.

\section{Author Contributions}

Conception and design: Lee, Perry, English, Alkherayf, Lesiuk, Moulton, Agbi, Sinclair, Dowlatshahi. Acquisition of data: Lee, Joseph, Nobile, Zhou, Dowlatshahi. Analysis and interpretation of data: Lee. Perry, English, Alkherayf, Lesiuk, Moulton, Agbi, Sinclair, Dowlatshahi. Drafting the article: Lee. Critically revising the article: Lee, Perry, English, Alkherayf, Dowlatshahi. Reviewed submitted version of manuscript: Lee, Perry, Dowlatshahi. Approved the final version of the manuscript on behalf of all authors: Lee. Statistical analysis: Lee, English, Dowlatshahi. Administrative/technical/material support: Lee. Study supervision: Perry, Dowlatshahi.

\section{Supplemental Information \\ Previous Presentations}

Portions of this work were previously presented in poster form at the 2017 American Association of Neurological Surgeons Annual Scientific Meeting, Los Angeles, California, April 2017.

\section{Correspondence}

Hubert Lee: The Ottawa Hospital, Ottawa, ON, Canada. hulee@ toh.on.ca. 